A. C. Riggs $\cdot$ E. Bernal-Mizrachi $\cdot$ M. Ohsugi $\cdot$

J. Wasson - S. Fatrai - C. Welling - J. Murray •

R. E. Schmidt · P. L. Herrera • M. A. Permutt

\title{
Mice conditionally lacking the Wolfram gene in pancreatic islet beta cells exhibit diabetes as a result of enhanced endoplasmic reticulum stress and apoptosis
}

Received: 23 March 2005 / Accepted: 1 June 2005 / Published online: 8 October 2005

(C) Springer-Verlag 2005

\begin{abstract}
Aims/hypothesis: Wolfram syndrome is an autosomal recessive disorder characterised by childhood diabetes mellitus, optic atrophy and severe neurodegeneration, resulting in premature death. The aim of this study was to investigate the mechanisms responsible for the phenotype of carbohydrate intolerance and loss of pancreatic beta cells in this disorder. Materials and methods: To study the role of the Wolfram gene $\left(W f_{S} 1\right)$ in beta cells, we developed a mouse model with conditional deletion of $W f_{s} 1$ in beta cells by crossing floxed $W f_{S} 1$ exon 8 animals with mice expressing Cre recombinase under the control of a rat insulin promoter (RIP2-Cre). Complementary experiments using RNA interference of $W f_{s} 1$ expression were performed in mouse insulinoma (MIN6) cell lines ( $W f S \mathrm{KD})$. Results: Male knockout mice $\left(\beta W f^{-1}\right)$ began developing variable and progressive glucose intolerance and concomitant insulin deficiency, compared with littermate controls, by 12 weeks of age. Analysis of islets from $\beta W_{f s}{ }^{--}$mice
\end{abstract}

A.C. Riggs and E. Bernal-Mizrachi contributed equally to this study.

A. C. Riggs · E. Bernal-Mizrachi - M. Ohsugi · J. Wasson ·

S. Fatrai $\cdot$ C. Welling $\cdot$ J. Murray $\cdot$ M. A. Permutt $(\triangle)$

Division of Endocrinology, Metabolism and Lipid Research,

Washington University School of Medicine,

660 S. Euclid Avenue,

Campus Box 8127, St Louis, MO 63110-1010, USA

e-mail: apermutt@,wustl.edu

Tel.: +1-314-3628680

Fax: +1-314-7472692

A. C. Riggs

Division of Pediatric Endocrinology and Metabolism,

Washington University School of Medicine,

St Louis, MO, USA

R. E. Schmidt

Department of Pathology and Immunology,

Washington University School of Medicine,

St Louis, MO, USA

\section{P. L. Herrera}

Department of Genetic Medicine and Development,

University of Geneva Medical School,

Geneva, Switzerland revealed a reduction in beta cell mass, enhanced apoptosis, elevation of a marker of endoplasmic reticulum stress (immunoglobulin heavy chain-binding protein $[\mathrm{BiP}]$ ), and dilated endoplasmic reticulum with decreased secretory granules by electron microscopy. WfsKD cell lines had significantly increased apoptosis and elevated expression of the genes encoding $\mathrm{BiP}$ and $\mathrm{C} / \mathrm{EBP}-$ homologous protein (CHOP), two markers of endoplasmic reticulum stress. Conclusions/interpretation: These results indicate that (1) lack of expression of $W f_{S} 1$ in beta cells was sufficient to result in the diabetes mellitus phenotype; (2) beta cell death occurred by an accelerated process of apoptosis; and (3) lack of $W f_{S} 1$ was associated with dilated endoplasmic reticulum and increased markers of endoplasmic reticulum stress, which appears to be a significant contributor to the reduction in beta cell survival.

Keywords Apoptosis - Beta cells - Diabetes mellitus . Endoplasmic reticulum stress - $W f_{S} 1$ - Wolfram syndrome Islets of Langerhans

Abbreviations BrdU: 5-bromo-2'-deoxyuridine - ER: endoplasmic reticulum $\cdot W f s \mathrm{KD}$ : Wolfram syndrome knockdown

\section{Introduction}

Wolfram syndrome is a rare autosomal recessive disorder characterised predominantly by juvenile onset insulindependent diabetes mellitus and optic atrophy $[1,2]$. The gene for Wolfram syndrome (WFS1) was identified by positional cloning in 1998 [3, 4], and was shown to be an endoplasmic reticulum (ER) membrane protein $[5,6]$ expressed at highest levels in brain, heart and pancreatic islets [3]. Based on association or linkage studies, WFS1 may influence susceptibility to type 2 [7] or type 1 [8] diabetes, although its role in these disorders remains uncertain.

The mechanisms involved in the development of diabetes in Wolfram syndrome remain obscure, but decreased pancreatic islet beta cell mass and disrupted islet archi- 
tecture have been observed, with no evidence of immunemediated destruction [9]. Based on homology with the previously described genes Sell and $\mathrm{Hrd} 3 p$ in lower organisms, WFS1 may serve to alleviate the ER stress that accompanies the unfolded protein response [10]. Recent data also suggest that the gene might be important in the regulation of intracellular calcium homeostasis [6]. Given current technologies, these possibilities are difficult to assess in affected individuals.

The present report describes the metabolic abnormalities of an animal (mouse) model with beta cell-specific deletion of $W f_{S} 1$ and extends the observations described by Ishihara et al. using conventional knockout mice [11]. Complementary to the in vivo model, the present work describes in addition the role of decreased $W f_{S} 1$ in vitro in insulinoma cell lines. The results of these studies indicate that $W f_{S} 1$ is critical to beta cell survival and that deficiency of $W f_{S} 1$ predisposes to diabetes through enhanced ER stress.

\section{Materials and methods}

Preparation of the construct for homologous recombination and generation of $W f_{S} l$ knockout mice

The targeting construct to introduce loxP sites into $W f_{S} 1$ was created from a $W f_{S} 1$-positive clone containing exon 8 from a $129 \mathrm{SvJ}$ mouse BAC genomic library screen (No. 24675, kindly supplied by Y. Oka, Tohoku University, Sendai, Japan). The 3.3-kb targeting vector using the 38LoxPNeo backbone (a modified version of pGT-N38 from New England Biolabs, Beverly, MA, USA) contained exon 7 , flanking intronic sequences, a $5^{\prime}$ loxP site, exon 8 , a neomycin-resistance cassette followed by a $3^{\prime}$ loxP site and $3^{\prime}$ untranslated region (UTR) sequence (Fig. 1a). Linearised 38LoxPNeo/Wfs 1 was transfected into embryonic stem cells derived from $129 \mathrm{SvJ}$ mouse blastocysts. Selection was performed with G418, a neomycin analogue, and 192 resistant clones were screened for homologous recombination by Southern blotting using $5^{\prime}$ and $3^{\prime}$ external probes and an internal neo probe. Targeted embryonic stem cells from two clones were microinjected into C57BL/6 mouse blastocysts. Generation of chimeric mice and germline transmission of the mutant allele were achieved using standard techniques. The RIP2-Cre animal was provided by P. Herrera [12].

\section{Genotype analysis}

Genomic PCR for the detection of the loxP allele was performed by extracting DNA from mouse tails.

Physiological and statistical analysis

Blood glucose, glucose tolerance tests, serum insulins and in vivo insulin secretion were measured for male mice only, as previously described [13]. Differences in values were a

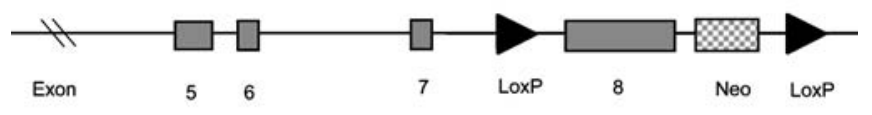

$b$
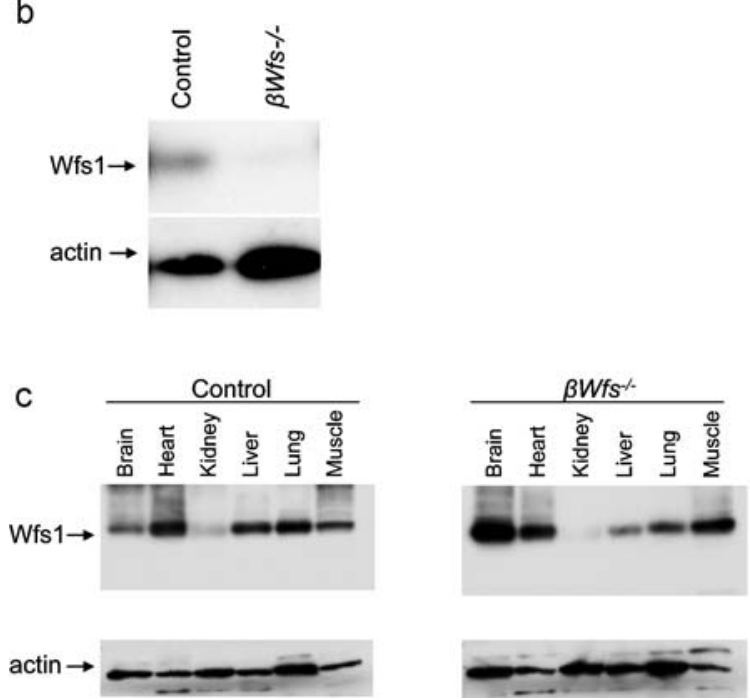

Fig. 1 a. Schematic diagram of the $\mathrm{COOH}$-terminal exons of $W f_{S} 1$ with engineered loxP sites flanking exon 8 which, on crossing with a RIP2-Cre mouse, results in a putative protein lacking the entire transmembrane domain and contains only the amino-terminal onethird of the $W f_{S} 1$ protein. b. Western blot analysis for Wfs 1 in isolated islets from 8- to 12 -week-old $\mathrm{BWf}^{-{ }^{-1}}$ and control animals. c. Western blot analysis of non-islet tissues of 8- to 12-week-old control and $\beta W F s^{-1-}$ animals

assessed by two-tailed $t$-test, and for insulin secretion we used the Wilcoxon signed rank test. Glucose concentrations were obtained in animals fasted for $6 \mathrm{~h}$.

\section{Western blotting}

Forty micrograms of protein was loaded on a 7\% polyacrylamide gel, electrophoresed, transferred to PVDF (polyvinylidene fluoride) membrane and $W f_{S} 1$ was detected by $\mathrm{N}$-terminal mouse $W f_{S} 1$ antibody (provided by $\mathrm{Y}$. Oka, Tohoku University, Sendai, Japan).

Isolation of mouse islets, histology, immunohistochemistry and islet morphology

Islets were isolated by collagenase digestion as described [13]. Antigens were retrieved by microwaving $(4 \mathrm{~min} \times 2)$ in $0.01 \mathrm{~mol} / 1$ sodium citrate and $0.01 \mathrm{~mol} / 1$ citric acid. Immunostaining for insulin and immunofluorescence was as described [13]. Detection of insulin was performed in five sections. The percentage of beta cell area in the pancreas was calculated from five sections separated by $200 \mu \mathrm{m}$ previously immunostained for insulin. The insulinstained area was divided by the exocrine area and the ratio was multiplied by the pancreas weight to obtain beta cell mass. 
Assessment of apoptosis and estimation of islet beta cell proliferation

Cleaved caspase 3 staining was measured with polyclonal anti-caspase 3 antibody (Biocarta, Carlsbad, CA, USA) at 1 : 500 dilution and the Histomouse-SP kit (Zymed Laboratories, South San Francisco, CA, USA) using 3-amino-9ethyl carbazole as chromogen. Islet cells were counted in a blinded fashion for positive caspase 3 staining and reported as percentage positive islet cells. Beta cell replication was determined by 5-bromo-2'-deoxyuridine (BrdU) incorporation on insulin and BrdU double-stained slides, as previously described [13].

\section{Electron microscopy}

Electron microscopy was performed in pancreases from mice dissected and sectioned in small fragments followed by fixation, staining with $4 \%$ uranyl acetate and embedding in Polybed 812 as described [14]. Thin sections were cut and viewed in a JEOL 1200 electron microscope. The images were analysed by an electron microscopist who was blinded to the experimental conditions. The beta cells were separated from alpha and delta cells by the appearance of the secretory granules. Beta cell granules have a white halo which is not apparent in alpha or delta cells (easily identified by the characteristic appearance of the granules) [15-17].

\section{Quantitative RT-PCR}

Total RNA was used to prepare cDNA using random hexamers, and reverse-transcribed with Superscript II (Invitrogen, Carlsbad, CA, USA) according to the manufacturer's protocol. Quantitative RT-PCR was performed by monitoring in real time the increase in fluorescence of the SYBR Green dye $(\mathrm{ABI})$ as described $[18,19]$ using the ABI 7000 sequence detection system (Applied Biosystems, Foster City, CA, USA). For comparison of transcript levels between samples, a standard curve of cycle thresholds for serial dilutions of a cDNA sample was established and then used to calculate the relative abundance of each gene. Values were then normalised to the relative amounts of $18 \mathrm{~S}$ rRNA (encoded by Rn18S) or Slc2a2 (formerly known as GLUT2) mRNA, which were obtained from a similar standard curve. All PCR reactions were performed as replicates of three. The standard error of the quantity of transcript normalised to the amount of $18 \mathrm{~S}$ rRNA or Scl2a2 mRNA was calculated from a formula with consideration of error propagation. Sequences of primers used in this study were: $W f_{s} 1,5^{\prime}$ CCAGCTGAGGAACTTCAAGG and $5^{\prime}$ AGGATGACCACGGACAGTTC; Slc2a2，5' CTGGGT CTGCAATTTTGTCA and 5' AGGCCCAAGGAAGTCC GCAA; Hspa5 (which encodes immunoglobulin heavy chain-binding protein $[\mathrm{BiP}]$ ), 5' TTCAGCCAATTATCA GCAAACTCT and 5' TTTTCTGATGTATCCTCTTCAC CAGT; Ddit3 (which encodes C/EBP-homologous protein
[CHOP]), 5' ATTGGGGGCACCTATATCTC and 5' TTG CTCTTCCTCCTCTTCCT; Rn18S, 5' GGTGGTGCATG GCCGTTCTTAGTT and 5' GCTGAACGCCACTTGTC CCTCTAA.

\section{Construction of small interfering RNA expressing plasmids}

A polIII-mediated small interfering RNA-expressing plasmid vector system (pSUPER vector) was constructed according to the methods described by Brummelkamp et al. [20]. Sixty-four-base DNA oligonucleotides, corresponding to sense target sequence, hairpin loop and anti-sense target sequence, were synthesised (Integrated DNA Technologies, Coraville, IA, USA), annealed together, and then ligated into BgIII- and HindIII-digested pSUPER vector. Plasmids were purified with Wizard Plus Maxipreps kit (Promega, Madison, WI, USA). The target sequence against mouse $W f_{s} 1$ in this study was GAAGTCCTGGAGAA AGCCA and the scrambled control sequence was CCCA GGCCCAGCATACCA.

Cell culture, transfection of insulinoma cells and selection of stably transfected clones

The MIN6 insulinoma cell line was used between passages 24 and 26 and was provided by J. Miyazaki [21]. Cotransfection of pSUPER vector and pcDNA 3.1 plasmid, which contains a neomycin-resistance cassette to facilitate the selection of stably transfected cells with G418, was performed as described [22]. After 4 weeks of selection with G418 (Mediatech, Herndon, VA, USA), colonies of the surviving cells (defined as passage 4) were selected. Protein levels and mRNA expression were tested at passage 7 or 8 , and clones were further maintained. MIN6-Con (E), MIN6-Con(S) and $W f_{s} \mathrm{KD}$ cells were used for experiments between passages 9 and 18 , which corresponded to passages 33 and 42 of the parental MIN6 cells.

\section{Measurement of apoptosis}

After plating for $48 \mathrm{~h}$ in standard media, cells were trypsinised and resuspended in annexin $\mathrm{V}$ buffer according to protocol (Annexin V-FITC [fluorescein isothiocyanate] Apoptosis Detection Kit; Biovision, Mountain View, CA, USA) and apoptosis was measured as the amount of annexin V-positive cells by flow cytometer.

\section{Results}

Conditional disruption of $W f_{S} 1$ in pancreatic islet beta cells and determination of tissue specificity

To generate a conditional $W f_{S} 1$ mouse model of Wolfram syndrome, we designed a targeting vector that contained 
Table 1 Weight and metabolic parameters in control and $\beta \mathrm{Wfs}^{-/-}$mice

\begin{tabular}{|c|c|c|c|c|c|c|c|c|c|c|}
\hline & \multicolumn{10}{|c|}{ Age (weeks) } \\
\hline & Control & $\beta W f^{-/-}$ & Control & $\beta W f^{-/-}$ & Control & $\beta W f^{-/-}$ & Control & $\beta W f^{-/-}$ & Control & $\beta W f^{-/-}$ \\
\hline Weight $(g)(n=6)$ & $15.8 \pm 0.6$ & $16.2 \pm 2.2$ & $22.7 \pm 1.4$ & $23.2 \pm 1.4$ & $27.8 \pm 1.0$ & $27.0 \pm 1.20$ & $27.4 \pm 1.5$ & $29.7 \pm 1.9$ & $33.0 \pm 1.1$ & $29.7 \pm 1.0^{*}$ \\
\hline $\begin{array}{l}\text { Fasting glucose } \\
(\mathrm{mmol} / \mathrm{l})(n \geq 6)\end{array}$ & - & - & $3.0 \pm 0.3$ & $3.2 \pm 0.2$ & $5.0 \pm 0.2$ & $5.6 \pm 0.5$ & $3.3 \pm 0.1$ & $5.7 \pm 2.5$ & $5.8 \pm 0.4$ & $8.8 \pm 1.8$ \\
\hline $\begin{array}{l}\text { Fed glucose } \\
(\mathrm{mmol} / \mathrm{l})(n \geq 6)\end{array}$ & $6.7 \pm 0.2$ & $6.1 \pm 0.1$ & - & - & $6.5 \pm 0.2$ & $7.6 \pm 0.8$ & - & - & $7.7 \pm 0.2$ & $12.8 \pm 2.4^{*}$ \\
\hline $\begin{array}{l}\text { Fed insulin } \\
(\mathrm{ng} / \mathrm{ml})(n \geq 6)\end{array}$ & - & - & - & - & $1.11 \pm 0.1$ & $0.78 \pm 0.06^{*}$ & - & - & $0.89 \pm 0.01$ & $0.53 \pm 0.12^{*}$ \\
\hline $\begin{array}{l}\text { Fasting glucose: } \\
\text { insulin }\end{array}$ & - & - & - & - & $8.0 \pm 0.8$ & $12.5 \pm 1.0^{*}$ & - & - & $7.9 \pm 1.3$ & $15.7 \pm 1.3 *$ \\
\hline $\begin{array}{l}\text { Beta cell: pancreas } \\
\text { ratio }(n=4)\end{array}$ & - & - & - & - & $1.2 \pm 0.1$ & $1.1 \pm 0.1$ & - & - & $1.7 \pm 0.2$ & $0.9 \pm 0.1^{*}$ \\
\hline
\end{tabular}

Statistical analysis was performed using two-tailed $t$-test. Significant value, ${ }^{*} p<0.05$ vs control

loxP sites flanking exon 8 of the gene (Fig. 1a). Exon 8 encodes the transmembrane domain and two-thirds of the protein, and the majority of the mutations in affected individuals are in this exon. Mice containing loxP sequences flanking exon 8 of the gene were crossed with mice expressing Cre recombinase under the control of the rat insulin promoter (RIP2-Cre) [12].

To confirm the deletion of $W f_{s} 1$ in pancreatic islets, lysates from animals lacking $W f_{S} 1$ in insulin-producing cells $\left(\beta \mathrm{Wf}_{S^{-/-}}\right)$and littermate loxP/loxP (control) animals were subjected to immunoblotting using an antibody that recognises an epitope encoded by exon 8 (Fig. 1b). Expression of $W f_{S} 1$ in non-islet tissues appeared to be preserved (Fig. 1c). These data suggest that the Cre-loxP system resulted in mice with marked deficiency of the Wfs 1 protein specifically in pancreatic islets.

General phenotypic characteristics

$\beta W f^{-1-}$ mice were born at expected Mendelian ratios with no differences in reproductive success. $\beta W f_{S}{ }^{-/}$animals and control animals had similar weights during the first 16 weeks of life, but at 24 weeks the $\beta W f_{S}^{-1-}$ animals had lower weights when compared with control mice (Table 1, $p<0.05$ ). The reduction in weight at 24 weeks occurred at a time when the $3 \mathrm{Wf}^{-/-}$mice had developed hyperglycaemia and insulinopenia relative to controls (Table 1).
Measurement of blood glucose, insulin and glucose tolerance

At $8,12,16$ and 24 weeks of age, mean fasted glucose concentrations did not differ between $\beta W F s^{-1-}$ and control animals (Table 1). Fed glucose concentrations were significantly higher in $\beta \mathrm{Wfs}^{--}$animals only at 24 weeks $(p<0.05)$. Fasting insulin levels were significantly reduced in the $\beta \mathrm{Wfs}^{-1-}$ mice at 12 weeks $(p<0.05)$. Fed insulin concentrations were significantly reduced in 12- and 24-
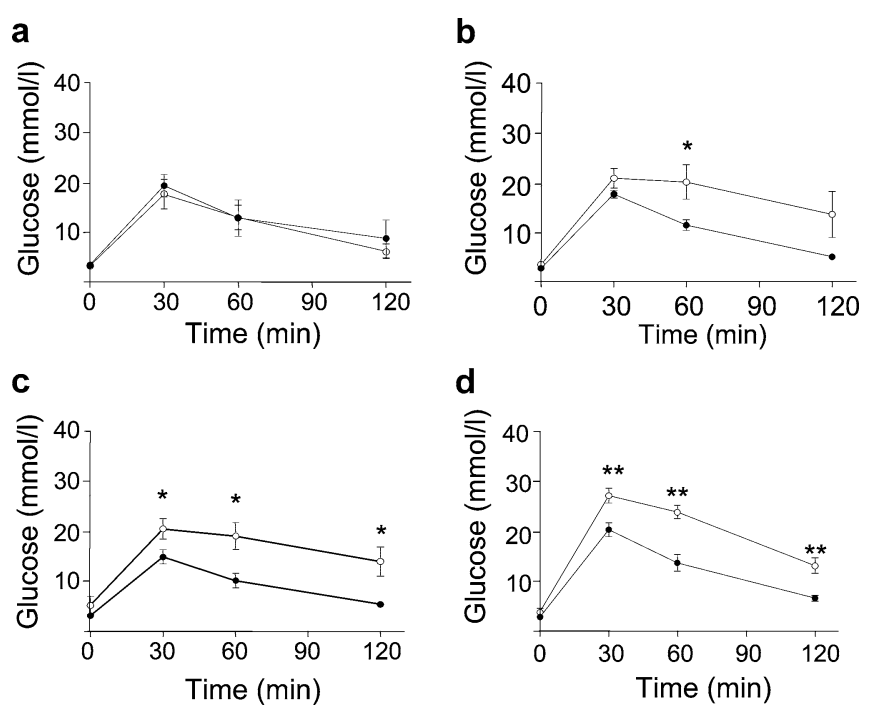

Fig. 2 IPGTT in control (closed circles) and $\beta \mathrm{Wfs}^{-/-}$(open circles) animals at (a) $8(n=6),($ b) $12(n=6),($ c) $16(n=11)$ and (d) $24(n=11)$ weeks. Data are means \pm SEM. $* p<0.05$ vs controls; $* * p<0.01$ vs controls 
a

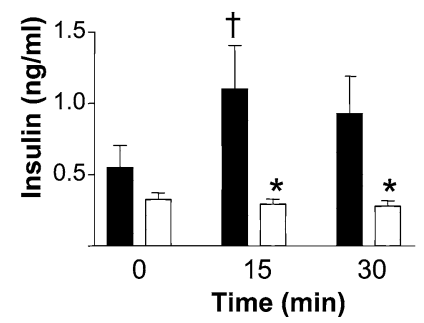

b

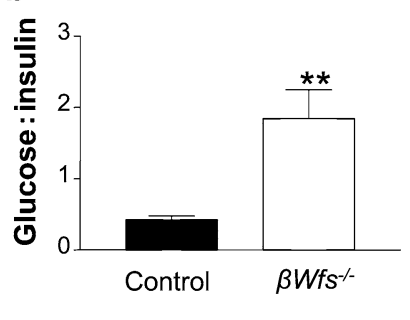

Fig. 3 a. Insulin levels 0,15 and 30 min after injection of glucose $(3 \mathrm{gm} / \mathrm{kg})$ in 12 -week-old control (black bars, $n=7)$ and $\beta W \mathrm{Ss}^{-/-}$ (white bars, $n=7$ ) animals. b Glucose : insulin ratios 30 min after glucose injection. Data are means \pm SEM. ${ }^{*} p<0.05$ vs control by $t$-test; ${ }^{* *} p<0.01$ vs control by $t$-test; ${ }^{\dagger} p<0.05$ vs control at time 0 by Wilcoxon signed rank test

week-old $\beta \mathrm{WfS}^{-1-}$ mice $(p<0.05)$. Both fasting and fed glucose : insulin ratios were elevated in $\beta \mathrm{Wfs}^{-/}$mice at 12 and 24 weeks of age $(p<0.05)$, further illustrating the insulinopenia for the degree of hyperglycaemia in these mice.

Glucose tolerance did not differ between the two groups at 8 weeks (Fig. 2a). By 12 weeks, mild glucose intolerance $60 \mathrm{~min}$ after glucose injection was observed in $\beta W f_{S}^{-1-}$ animals (Fig. 2b). Glucose tolerance in 16-weekold $3 \mathrm{Wf}_{S}^{-1-}$ animals was significantly impaired 30,60 and $120 \mathrm{~min}$ after glucose injection (Fig. 2c, $p<0.05$ ). By 24 weeks, nearly all $\beta \mathrm{WfS}^{-1-}$ animals exhibited significant glucose intolerance $(p<0.01)$ (Fig. $2 \mathrm{~d})$. Moreover, two of 13

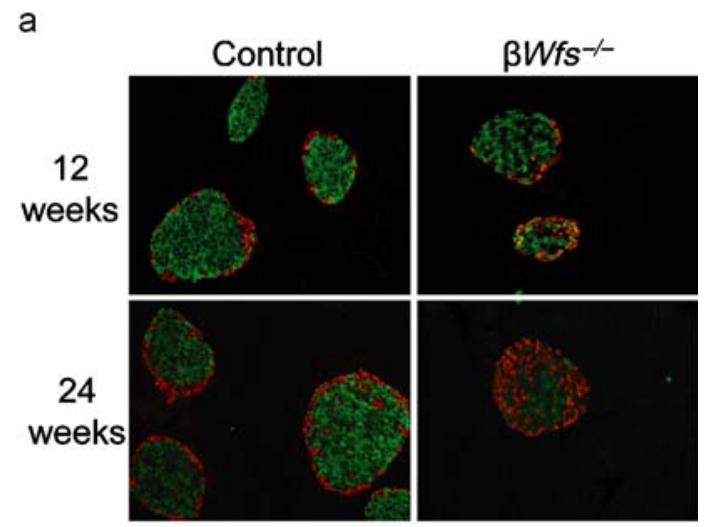

b

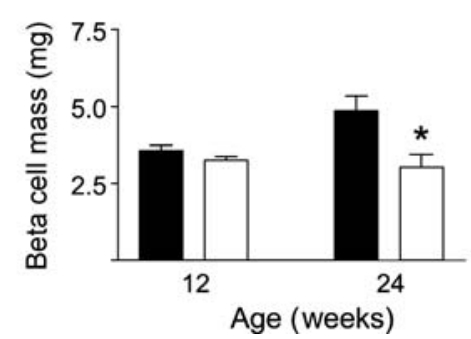

Fig. 4 Immunofluorescence of islets from control and $\beta \mathrm{Wfs}^{-/}$ animals at 12 and 24 weeks. a. Insulin-containing cells are stained green, whereas glucagon, somatostatin and pancreatic polypeptide cells are stained red. By 24 weeks, the $\beta W f_{S}{ }^{-1-}$ islets have markedly decreased insulin staining. b. Beta cell mass in control (black bars, $n=4)$ and $\beta \mathrm{WfS}^{-1-}$ (white bars, $n=4$ ) animals. Data are means \pm SEM. $* p<0.05$ vs controls

animals had developed severe fasting hyperglycaemia by this age, one of which died at 20 weeks of age. The RIP2Cre mice used in these studies had glucose tolerance that was not different from the loxP/loxP littermate control mice or wild-type mice (data not shown). The results of these experiments indicated that conditional inactivation of $W f_{S} 1$ in pancreatic beta cells results in progressive glucose intolerance and diabetes.

Impaired glucose-stimulated insulin secretion in $\beta W f^{-/-}$mice

To further assess beta cell function in $\beta \mathrm{Wf}_{S^{-/-}}$mice, insulin secretion was evaluated. As seen in Fig. $3 \mathrm{a}$, the glucosestimulated insulin responses were significantly impaired in $\beta W f_{S}{ }^{-1-}$ animals $(p<0.05)$. Comparison of the glucose : insulin ratio at 30 min further illustrated the impairment in insulin secretion in the $\beta \mathrm{Wfs}^{-/-}$animals (Fig. 3b).

Alterations in islet morphology and beta cell mass

Immunostaining for insulin and non-beta cells (somatostatin, glucagon and pancreatic polypeptide) showed that control animals at 12 and 24 weeks had the characteristic appearance of islets, with abundant beta cells in the centre and a rim of non-beta cells at the periphery (Fig. 4a). In contrast, although the beta cell mass did not differ between $\beta \mathrm{WfS}^{--}$and control (Fig. 4b), asymmetry and disruption of

a

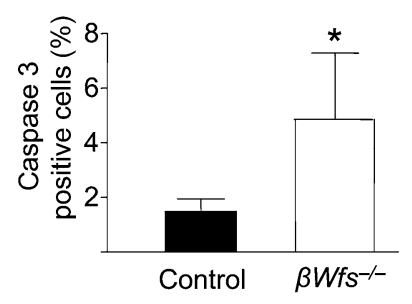

C

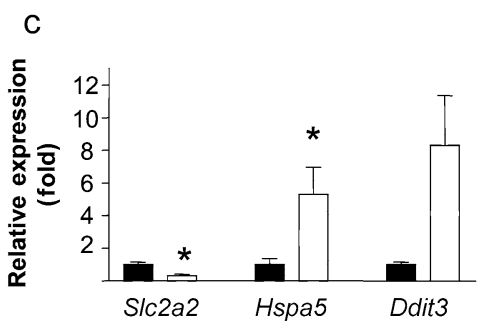

Fig. 5 a. Caspase 3-positive cells detected by immunohistochemistry in 12-week-old control (black bars) and $\beta \mathrm{Wfs}^{-/-}$(white bars) animals. The number of beta cells counted was 500-1500. b. BrdU incorporation in 12- and 24-week-old control (black bars) and $\beta \mathrm{WfS}^{-1}$ (white bars) mice. The number of nuclei counted per section was 500-1500. c. RT-PCR of Slc2a2, Hspa 5 and Ddit 3 mRNA of islets isolated from 8 - to 12 -week-old control (black bars) and $\beta \mathrm{Wfs}^{-/}$ (white bars) mice reported as relative (fold) expression. The expression of Slc2a2 is corrected for $18 \mathrm{~S}$ rRNA. The expression levels of Hspa 5 and Ddit 3 are corrected for Slc2a2 expression. Data were derived from 12-week-old control $(n=5)$ and $\beta W f_{S}^{-l-}(n=5)$ mice. Data are means \pm SEM. ${ }^{*} p<0.05$ vs control 
islet architecture was already apparent and was correlated with the relative hypoinsulinaemia at 12 weeks of age. At 24 weeks, there was further disruption of islet architecture, with marked alteration of the ratio of beta to non-beta cells within the islet. Pancreas weight in 12- and 24-week-old mice was not different between the groups (Table 1). Neither the beta cell : pancreas ratio nor beta cell mass was different at 12 weeks (Table 1 and Fig. 4b). Reduction of the beta cell : pancreas ratio and beta cell mass in $\beta \mathrm{Wfs}^{-1-}$ mice was observed at 24 weeks of age, suggesting that the decrease in beta cell mass was one of the components responsible for diabetes in $\beta \mathrm{Wfs}^{-/-}$mice (Table 1 and Fig. 4b).

Assessment of apoptosis and proliferation

In the $\beta W W f s^{--}$mice at 24 weeks of age the apparent beta cell dysfunction could result from impaired proliferation or enhanced apoptosis of beta cells. Pancreatic islets were examined by immunohistochemistry with an antibody to the active subunit of cleaved caspase 3 [23, 24]. A significant increase in caspase 3-positive nuclei in $\beta \mathrm{WfS}^{-{ }^{-}}$ animals compared with control animals at 12 weeks of age was noted $(p<0.05)$ (Fig. 5a). This 2.5-fold increase in caspase 3-positive cells in $\beta \mathrm{Wfs}^{-/-}$animals could be an explanation for the reduced beta cell mass and diabetes noted in this model. The frequency of beta cells that were BrdU- and insulin-positive revealed no differences between control and $\beta W f^{-1-}$ animals at 12 weeks or 24 weeks (Fig. 5b).

Increased ER stress in beta cells from $\beta W f s^{--}$mice

ER stress was assessed by measuring the relative levels of expression of mRNA encoding the ER stress-associated proteins $\mathrm{BiP}\left(H_{s p a 5}\right)$ and CHOP (Ddit3). Given that markedly fewer beta cells in knockout animals, ER stress mRNA expression was normalised to Slc2a2 mRNA instead of $18 \mathrm{~S}$ rRNA to reflect more accurately the expression of ER stress proteins, specifically in beta cells.
Fig. 6 Ultrastructural analysis using electron microscopy in islets from 12-week-old $\beta \mathrm{Wfs}^{-1}$ and control mice. Electron micrographs for sections of islets from control and $\beta W f_{S}{ }^{-1-}$ mice at different magnifications. Scale bars correspond to $5 \mu \mathrm{m}(\mathbf{a}), 2 \mu \mathrm{m}$ (b) and $500 \mathrm{~nm}$ (c). N, nucleus; SG, secretory granules; RBC, red blood cells. The short arrows in (c) indicate dilated ER in beta cells from

$\beta W f^{-/-}$vs control mice
Control

a

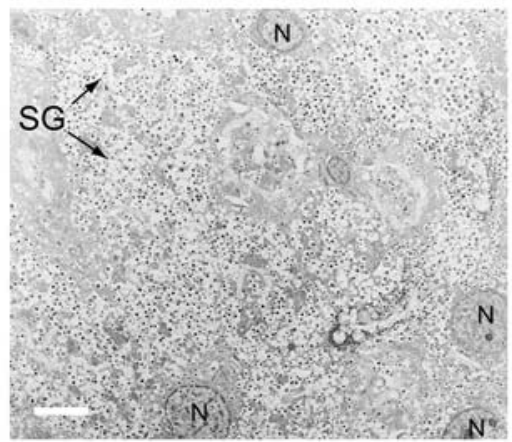

b

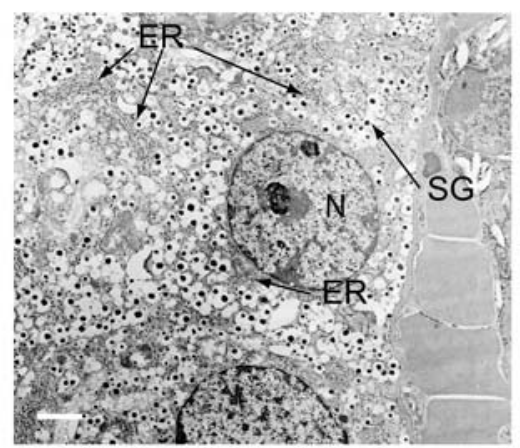

C

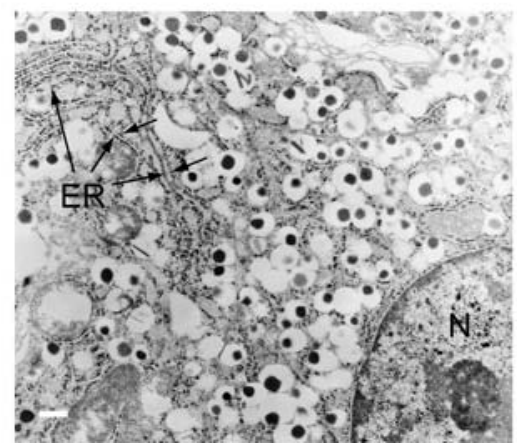

$\beta W f s^{-/-}$
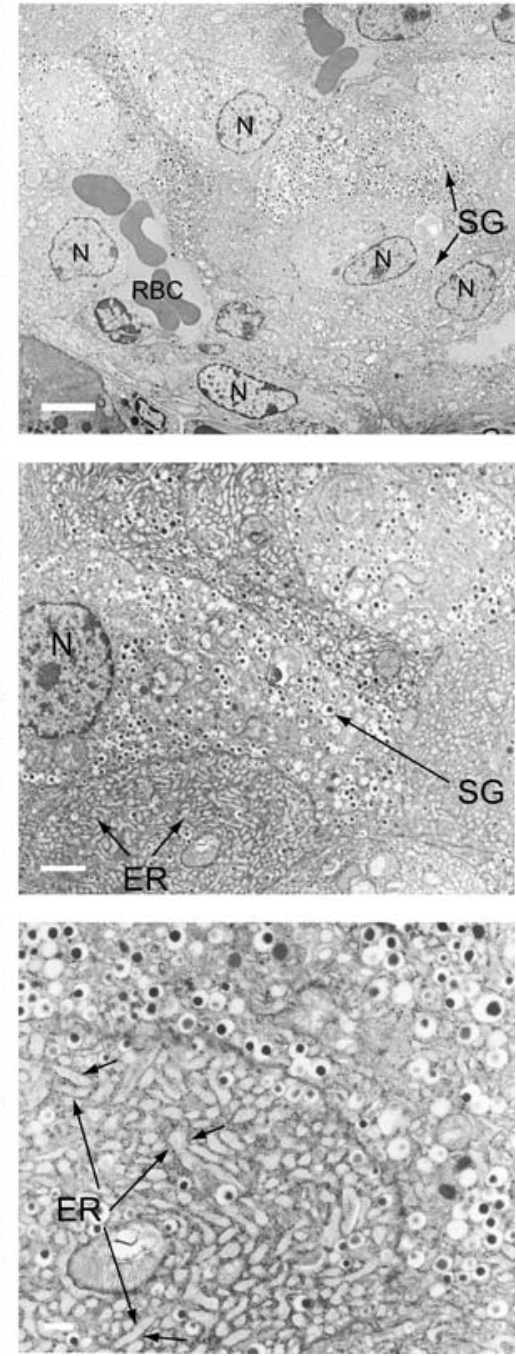
Slc2a2 expression was decreased in proportion to the decrease in beta cell mass when normalised to $18 \mathrm{~S}$ RNA, suggesting that $S l c 2 a 2$ expression was not significantly altered (Fig. 5c). When corrected for Slc2a2 expression as a reflection of the percentage of beta cells per islet, Hspa 5 expression was significantly elevated in islets from $3 \mathrm{WfS}^{-1-}$ animals compared with controls $(p<0.05)$, whereas Ddit3 expression appeared elevated but did not reach statistical significance (Fig. 5c).

To further substantiate the increased levels of ER stress in beta cells from $\beta \mathrm{Wfs}^{-1-}$, pancreas was examined by electron microscopy (Fig. 6). The beta cells were distinguished from alpha and delta cells by the appearance of the secretory granules. The beta cell granules have a white halo, which is not apparent in alpha or delta cells. Homogeneous distribution of secretory granules was observed in beta cells from control animals (Fig. 6a). Ultrastructural analysis of $\beta \mathrm{Wfs}^{-{ }^{--}}$pancreas revealed striking abnormalities in beta cell morphology, with some cells more affected than others (Fig. 6b). Higher magnification more clearly shows that beta cells from control mice exhibit abundant secretory granules, with the normal morphological appearance of the ER (Fig. 6b and c). In contrast, beta cell secretory granules from $\beta \mathrm{Wfs}^{-1-}$ islets appeared to be reduced and the majority of the beta cells exhibited abundant dilated ER (Fig. $6 b$ and c). These abnormalities were more significant in some beta cells from $\beta W_{f s}^{--}$mice and were never observed in multiple sections from age-matched control animals.

Studies using MIN6 cells containing knockdown of $W f_{S} 1$

To further elucidate the molecular mechanisms of deficiency of $W f_{s} 1$ expression on beta cell survival and insulin secretion, stable cell lines with reduced $W f_{S} 1$ expression were created using RNA interference in MIN6 insulinoma cells. The reduction in $W f_{S} 1$ expression was confirmed in two cell lines relative to that in two control cell lines. The controls for these experiments included MIN6 cells stably transfected with pSUPER plasmid containing no additional sequences (MIN6-Con(E)) and a second control containing pSUPER with a sequence identical to $W f_{s} 1$-specific sequence, except for two mismatched base pairs (MIN6-Con (S)), which served as a scrambled control. Both control lines had no alterations in expression of $W f_{s} 1$ (Fig. 7a). Cell lines with $50 \%\left(W f_{S} \mathrm{KD} 50\right)$ and $70 \%\left(W f_{s} \mathrm{KD} 70\right)$ reduction in $W f_{s} 1$ expression and Wfs1 production (Fig. 7a and b, respectively) were used for these experiments.

Evaluation of apoptosis in cell lines with reduced expression of $W f_{s} 1$

To confirm the role of apoptosis in the alterations of beta cell mass found in vivo, we next evaluated the in vitro model of $W f_{S} 1$ deficiency. Apoptosis was measured by the number of annexin V-positive cells counted by flow cy-

tometry. As seen in Fig. 7c, the two knockdown cell lines, $W f S \mathrm{KD} 50$ and $W f \mathrm{~K}$ KD70, exhibited increased apoptosis when cultured under standard conditions $(19.8 \pm 3.6 \%$ and $17.3 \pm 1.3 \%$ respectively compared with MIN6-Con(E) control, $8.3 \pm 0.7 \% ; p<0.05$ ). Thus, the in vitro observations were consistent with the in vivo results and supported the conclusion that $W f_{S} 1$ is required for pancreatic islet beta cell survival.

\section{Evaluation of ER stress in $W f_{s} \mathrm{KD}$ cells}

The expression of the gene encoding the molecular chaperone $\mathrm{BiP}\left(H_{s p a 5}\right)$, a protein associated with ER stress, was elevated in both knockdown cell lines $(p<0.05)$ (Fig. 7d). The expression of the gene for CHOP (Ddit3), a protein integral in the apoptosis pathway that accompanies ER stress, was also significantly elevated in the $W f_{s} \mathrm{KD} 70$ cells $(p<0.05)$ (Fig. 7e). These data are again consistent with

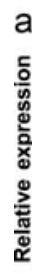
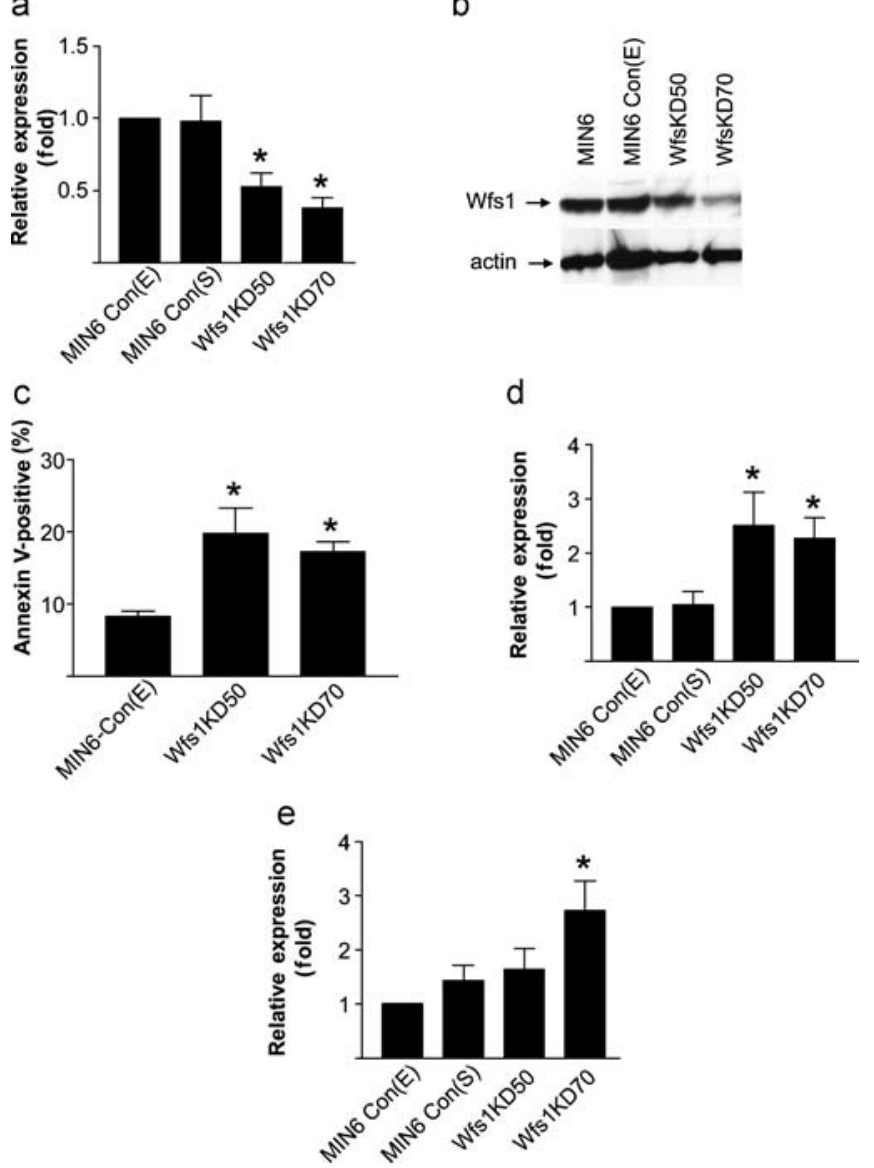

Fig. 7 a. RT-PCR of $W f s 1$ expression in MIN6-Con(E), MIN6-Con (S), Wfs1KD50 and Wfs1KD70 cells reported as relative (fold) expression. b. Western blot of MIN6, MIN6-Con(E), WfsKD50 and Wfs1KD70. c. Analysis of apoptosis by flow cytometry of MIN6Con(E), Wfs1KD50 and Wfs1KD70 cells stained for annexin V. RTPCR of (d) Hspa5 and (e) Ddit3 expression in MIN6-Con(E), MIN6-Con(S), Wfs1KD50 and Wfs1KD70 cells reported as relative (fold) expression. Values are representative of two experiments done in triplicate. Data are means \pm SEM. ${ }^{*} p<0.05$ vs MIN6-Con(E) 
those seen in the in vivo model, further suggesting that ER stress is associated with apoptosis in these models.

\section{Determination of insulin secretion of in $W f s \mathrm{KD}$ cells}

The in vivo model suggested a defect in insulin secretion (Fig. 3a). The in vitro system allowed the assessment of insulin secretion in the absence of metabolic abnormalities induced by chronic hyperglycaemia in vivo. Following correction for insulin content, there was no difference in glucose-stimulated insulin secretion between knockdown cell lines and controls (data not shown).

\section{Discussion}

In this study, a pancreatic islet beta cell-specific knockout of $W f_{S} 1$ in mice resulted in a model in which the natural history and mechanisms of beta-cell dysfunction can be studied. Total disruption of $W f_{S} 1$ was recently accomplished by insertion of a neomycin-resistance gene in exon 2, which contains the ATG initiation codon [11]. Phenotypic changes were similar to those reported here with tissue-specific knockout of the gene, i.e. mild glucose intolerance in mice at 16-17 weeks of age, overt diabetes in over half the mice beyond 24 weeks of age, impaired glucose-stimulated insulin secretion, and reduced pancreatic insulin content and beta cell mass. One phenotypic characteristic that differed between the total and tissuespecific knockout models was the presence of increased insulin sensitivity in the former. The present study importantly extends the observations reported for the total knockout in several ways. First, the glucose intolerance of the complete knockout may be partially altered by changes in insulin sensitivity, while the beta cell-specific knockout of $W f_{S} 1$ demonstrated that the carbohydrate metabolic abnormalities resulted from deficiency of $W f_{s} 1$ specifically in beta cells. Second, in the previous report apoptosis was not demonstrated in vivo and was only reported in isolated islets subjected to high glucose or agents that induce ER stress. In the present report, evidence that apoptosis was a contributing mechanism for reduced beta cell mass was demonstrated by both in vivo and in vitro assays under non-stressed conditions. Third, the present study demonstrated for the first time that disruption of $W f_{s} 1$ was associated with elevation of markers of ER stress and structural abnormalities of the ER in vivo. Fourth, in the present study stable MIN6 cell lines with reduction in $W f_{s} 1$ expression were created and used to confirm the in vivo observations of increased apoptosis and ER stress. Finally, in the previous report there was a modest defect $(23 \%)$ in stimulus-secretion coupling in isolated islets when corrected for the reduction in insulin content. In the present study insulin secretion in $W f_{S} 1$ knockdown cells was normal, suggesting that the principle mechanism for impaired insulin secretion in vivo results from loss of beta cells via enhanced ER stress, with resultant apoptosis.
The glucose intolerance in male $\beta W f_{s}{ }^{-/-}$mice started as early as 12 weeks, progressed with age and some animals (two out of 13) exhibited overt diabetes. The variable penetrance of the phenotype could be explained by the mixed background. This defect resulted from impaired glucosestimulated insulin secretion (Fig. 3a). However, at this point it was not possible to distinguish a primary secretory defect from one due to diminished islet beta cell mass. The decreased number or absence of secretory granules found by electron microscopy in beta cells from $\beta \mathrm{Wfs}^{-1}$ mice suggest the presence of an insulin secretory defect. Further evaluation of this apparent secretory defect was hampered because isolation of islets resulted in a low yield of islets from $\beta W f^{-1-}$ animals. These $\beta W s^{-/-}$islets were grossly smaller and less tolerant to experimental manipulation, making the in vitro study of $\beta \mathrm{Wfs}^{-1-}$ islet physiology and insulin secretion quite challenging. For these reasons, stable MIN6 cell lines deficient in $W f_{S} 1$ expression were engineered to allow us to study some of the mechanisms that could explain the in vivo model. $W f s \mathrm{KD}$ cell lines exhibited impaired insulin secretion in response to glucose challenge, while insulin content was decreased by 50 and $70 \%$ in $W f_{S} \mathrm{KD} 50$ and $W f_{S K D} \mathrm{T0}$, respectively (data not shown). Thus, in contrast to observations in mice with total knockout of $W f_{S} 1$ [25], the results of these studies provide no evidence of a primary defect of insulin secretion that is disproportionate to the decrease in beta cell mass.

These studies provide both in vivo and in vitro evidence that the clinical picture of Wolfram syndrome is the result of accelerated apoptosis. A mechanism for apoptosis associated with ER stress in Wolfram syndrome has been proposed because the homology with SEL1 and Hrd3p, proteins important for the regulation of ER stress in lower organisms [10]. Cells that have high engagement of ER apparatus, such as oligodendrocytes and beta cells, may be at increased risk of susceptibility to ER stress [26, 27]. Remarkably, the $\beta W f_{S}{ }^{-/}$mice and $W f_{S} 1$-deficient cell lines had a highly significant increase in expression of the genes encoding the ER stress markers BiP and CHOP, and dilated ER, suggesting that ER stress may play a role in the apoptosis of beta cells, and perhaps in neurons, in patients with this disorder.

Acknowledgements We gratefully acknowledge B. Wice, L. J. Muglia, S. Martinez, L. Love-Gregory and C. Cras-Méneur for helpful suggestions and stimulating discussions, S. Vance and G. Skolnick for administrative assistance, and M. Shornick and Incyte Genomics for technical assistance. We also would like to acknowledge D. Accili for facilitating transfer of the RIP2-Cre mice.

This work was supported in part by National Institutes of Health, National Research Service Award 1-T32-HD043010 from the National Institute of Child Health and Human Development and institutional training grant T32-DK063706 from the National Institutes of Health (A. C. Riggs), American Diabetes Association and National Institutes of Health (E. Bernal-Mizrachi), the Swiss National Science Foundation, the Juvenile Diabetes Research Foundation and the NIH/NIDDK's Beta Cell Biology Consortium (P. L. Herrera), National Institutes of Health grants DK16746, DK56954, DK99007 (M. A. Permutt), DK19645 and AG10299 (R. E. Schmidt), and the Washington University Diabetes Research and Training Center. 


\section{References}

1. Minton JA, Rainbow LA, Ricketts C, Barrett TG (2003) Wolfram syndrome. Rev Endocr Metab Disord 4:53-59

2. Barrett TG, Bundey SE (1997) Wolfram (DIDMOAD) syndrome. J Med Genet 34:838-841

3. Inoue H, Tanizawa Y, Wasson J, Behn P, Kalidas K, BernalMizrachi E et al (1998) A gene encoding a transmembrane protein is mutated in patients with diabetes mellitus and optic atrophy (Wolfram syndrome). Nat Genet 20:143-148

4. Strom TM, Hortnagel K, Hofmann S, Gekeler F, Scharfe C, Rabl W et al (1998) Diabetes insipidus, diabetes mellitus, optic atrophy and deafness (DIDMOAD) caused by mutations in a novel gene (wolframin) coding for a predicted transmembrane protein. Hum Mol Genet 7:2021-2028

5. Takeda K, Inoue H, Tanizawa Y, Matsuzaki Y, Oba J, Watanabe $Y$ et al (2001) WFS1 (Wolfram syndrome 1) gene product: predominant subcellular localisation to endoplasmic reticulum in cultured cells and neuronal expression in rat brain. Hum Mol Genet 10:477-484

6. Osman AA, Saito M, Makepeace C, Permutt MA, Schlesinger P, Mueckler M (2003) Wolframin expression induces novel ion channel activity in endoplasmic reticulum membranes and increases intracellular calcium. J Biol Chem 278:52755-52762

7. Minton JA, Hattersley AT, Owen K, McCarthy MI, Walker M, Latif $F$ et al (2002) Association studies of genetic variation in the WFS1 gene and type 2 diabetes in UK populations. Diabetes 51:1287-1290

8. Larsen ZM, Johannesen J, Kristiansen OP, Nerup J, Pociot F (2004) Evidence for linkage on chromosome 4p16.1 in Type 1 diabetes Danish families and complete mutation scanning of the WFS1 (Wolframin) gene. Diabet Med 21:218-222

9. Karasik A, O’Hara C, Srikanta S, Swift M, Soeldner JS, Kahn CR, Herskowitz RD (1989) Genetically programmed selective islet beta-cell loss in diabetic subjects with Wolfram's syndrome. Diabetes Care 12:135-138

10. Harding HP, Ron D (2002) Endoplasmic reticulum stress and the development of diabetes: a review. Diabetes 51(Suppl 3): S455-S461

11. Ishihara H, Takeda S, Tamura A, Takahashi R, Yamaguchi S, Takei D et al (2004) Disruption of the WFS1 gene in mice causes progressive beta-cell loss and impaired stimulus-secretion coupling in insulin secretion. Hum Mol Genet 13:11591170

12. Herrera PL (2000) Adult insulin- and glucagon-producing cells differentiate from two independent cell lineages. Development 127:2317-2322

13. Bernal-Mizrachi E, Wen W, Stahlhut S, Welling C, Permutt MA (2001) Islet $\beta$ cell expression of constitutively active Akt1/PKB induces striking hypertrophy, hyperplasia, and hyperinsulinemia. J Clin Invest 108:1631-1638
14. Shyng SL, Heuser JE, Harris DA (1994) A glycolipid-anchored prion protein is endocytosed via clathrin-coated pits. J Cell Biol 125:1239-1250

15. Straub SG, Shanmugam G, Sharp GW (2004) Stimulation of insulin release by glucose is associated with an increase in the number of docked granules in the beta-cells of rat pancreatic islets. Diabetes 53:3179-3183

16. Mythili MD, Vyas R, Akila G, Gunasekaran S (2004) Effect of streptozotocin on the ultrastructure of rat pancreatic islets. Microsc Res Tech 63:274-281

17. Gopel S, Zhang Q, Eliasson L, Ma XS, Galvanovskis J, Kanno $T$ et al (2004) Capacitance measurements of exocytosis in mouse pancreatic alpha-, beta- and delta-cells within intact islets of Langerhans. J Physiol 556:711-726

18. Morrison TB, Weis JJ, Wittwer CT (1998) Quantification of low-copy transcripts by continuous SYBR Green I monitoring during amplification. Biotechniques 24:954-958; 960, 962

19. Wittwer CT, Herrmann MG, Moss AA, Rasmussen RP (1997) Continuous fluorescence monitoring of rapid cycle DNA amplification. BioTechniques 22:130-131; 134-138

20. Brummelkamp TR, Bernards R, Agami R (2002) A system for stable expression of short interfering RNAs in mammalian cells. Science 296:550-553

21. Miyazaki J, Araki K, Yamato E, Ikegami H, Asano T, Shibasaki Y, Oka Y, Yamamura K (1990) Establishment of a pancreatic beta cell line that retains glucose-inducible insulin secretion: special reference to expression of glucose transporter isoforms. Endocrinology 127:126-132

22. Ohsugi M, Cras-Meneur C, Zhou Y, Bernal-Mizrachi E, Johnson JD, Luciani DS et al (2005) Reduced expression of the insulin receptor in mouse insulinoma (MIN6) cells reveals multiple roles of insulin signaling in gene expression, proliferation, insulin content, and secretion. J Biol Chem 280:49925003

23. Moritz W, Meier F, Stroka DM, Giuliani M, Kugelmeier P, Nett PC et al (2002) Apoptosis in hypoxic human pancreatic islets correlates with HIF-1alpha expression. FASEB J 16:745-747

24. Jhala US, Canettieri G, Screaton RA, Kulkarni RN, Krajewski $\mathrm{S}$, Reed J et al (2003) cAMP promotes pancreatic beta-cell survival via CREB-mediated induction of IRS2. Genes Dev 17:1575-1580

25. Ishihara H, Asano T, Tsukuda K, Katagiri H, Inukai K, Anai M et al (1994) Overexpression of hexokinase 1 but not GLUT1 glucose transporter alters concentration dependence of glucosestimulated insulin secretion in pancreatic beta-cell line MIN6. J Biol Chem 269:3081-3087

26. Ma Y, Hendershot LM (2004) Herp is dually regulated by both the endoplasmic reticulum stress-specific branch of the unfolded protein response and a branch that is shared with other cellular stress pathways. J Biol Chem 279:13792-13799

27. Bertolotti A, Zhang Y, Hendershot LM, Harding HP, Ron D (2000) Dynamic interaction of BiP and ER stress transducers in the unfolded-protein response. Nat Cell Biol 2:326-332 